\title{
EYE INJURIES AT WORK: A PROSPECTIVE POPULATION-BASED SURVEY WITHIN THE CHEMICAL INDUSTRY
}

\author{
NICHOLAS P. JONES and GUY A. P. GRIFFITH \\ Manchester
}

\begin{abstract}
SUMMARY
A population of 63,000 chemical industry workers was studied prospectively over approximately $10,000,000$ man-hours of work. A total of 133 eye injuries were reported (8.4\% of all injuries), of which $22 \%$ needed medical attention. Eye protection was often not worn, some protectors may have been wrongly recommended for a particular task, and some protectors may have failed to perform adequately. In this population, an eye injury occurred once every 75,000 man-hours of work on average (injury incidence 23:1000:year). Most injuries were avoidable. Revision of protection protocols at work, and improved education of personnel are needed to reduce the incidence of occupational eye injury.
\end{abstract}

Eye injuries of occupational origin have been a source of concern to ophthalmologists since the first important survey of eye injuries ${ }^{1}$ demonstrated that $71 \%$ of all severe eye injuries admitted to hospital were sustained at work. Most of these occurred in engineering workers, workers with hot metal, and coal miners. More than $12 \%$ of eyes were enucleated. Only four of 1,000 severe injuries were sustained by chemical workers.

Since Garrow's paper ${ }^{1}$ of 1923, the nature of occupational eye injuries has changed. Legislation has been introduced in the form of The Factories Act 1961 and the supplemental Protection of Eyes Regulations $1974^{2}$ The organisation of industry has improved but the variety of manufacturing processes has vastly increased, in the chemical industry more than any other. Lambah, in $1968^{3}$, while still finding a high proportion of occupational injuries in the total of more than 1,000 (excluding children) admitted to hospital, found that chemical workers occupied $5 \%$ of the total.

Severe eye injuries at work, necessitating admission to hospital, are becoming more uncommon, largely due to safer practices and the use of ocular protection. In the

Correspondence to: Mr N. P. Jones, University Department of Ophthalmology, Manchester Royal Eye Hospital, Oxford Road, Manchester M13 9WH. 1970s, Canavan et al. ${ }^{4}$ found that occupational eye injuries had fallen to $15 \%$ of the total (the proportion of road accidents having risen above it), and in 1989, MacEwen ${ }^{5}$ found $14 \%$ of admissions were of occupational origin, being only the fourth commonest cause of severe injury (after sport and leisure, domestic and assault).

However, admissions to hospital, with a severe eye injury, account for a very small proportion of the eye injuries which require attention at an ophthalmic casualty department $\left(0.9 \%\right.$, Jones et al. $1986^{6}, 1.8 \%$, MacEwen $1989^{5}$ ). MacEwen found that in $1989,70 \%$ of all eye injuries attending the department in Glasgow were workrelated (3,963 of 5,671 injuries). Ninety-nine percent of these were male, and $85 \%$ were wearing no ocular protection when injured.

Severe eye injuries admitted to hospital are the 'tip of the iceberg' of ophthalmic injury, as seen in ophthalmic casualty departments. Are those injuries attending hospital the tip of a greater iceberg, those which never attend hospital? To date there is no study which can answer that question. This study examines a large population of people at work for a substantial time period, in a particular industry, and attempts to find the true incidence of eye injury in this type of work and to find methods of reducing this incidence.

\section{METHODS}

This study looked prospectively at eye injuries sustained in the chemical industry during the month of February 1991 and retrospectively during the year to February 1st 1991. The chemical industry is the United Kingdom's third biggest manufacturing sector, behind food, drink and tobacco, and mechanical engineering, and employs approximately 280,000 people. Its main trade/employer organisation is the Chemical Industries Association (CIA), representing about 200 companies. All member companies were contacted by the CIA itself, with a request to voluntarily participate in this survey. Each company received three questionnaire-type documents: 
The first document (Company Details Sheet, CDS) requested details of the company itself, including the size of the workforce, hours worked and the provision of medical and nursing care.

The second document (Injury Summary Sheet, ISS) requested a summary of the injuries sustained during the study month, with details of their management, disposal and outcome. It compared the frequency and severity of eye injuries with other injuries. It also requested a summary of eye injuries sustained during the preceding year.

The third document (Eye Injury Sheet, EIS) was to be completed for each employee sustaining an eye injury during the month of February. It detailed the nature of employment, the procedure being performed at the time of injury, the type of eye protection recommended for this procedure, the injury sustained, and the type of eye protection (if any) being worn at the time of the injury. The medical care necessary was outlined, time off work recorded, and the opinion of the doctor or nurse was requested, on how that particular injury could have been avoided.

This paper reports on the general results of the survey, safety aspects of this industry, and ocular protection. Data specifically related to chemical injuries of the eye will be reported elsewhere.

\section{RESULTS}

A total of 53 companies (with a workforce on 111 sites) responded to the CIA's request to participate in the survey (reply rate approximately $25 \%$ ). The personnel responsible for providing information are listed in Table I.

The sample included large and small companies, with a minimum workforce of seven and a maximum of 9,000. Some companies were on a single site, others were on multiple sites (maximum 20). The total workforce was 62,839 . The prospective survey period covered four weeks in February 1991 and studied approximately 10,000,000 man-hours of labour.

Of the 111 sites, 83 retained a medical officer. Sixtyfour sites employed a nurse at some time, and 59 had a nurse on site for 40 hours or more per week. Twenty one nurses had special ophthalmic training. At other times, and on sites where no nursing care was available, first aiders provided emergency care.

The injuries sustained during the study month and during the preceding year are summarised in Table II. Six-

Table I. Personnel providing questionnaire information

\begin{tabular}{lrrr}
\hline Questionnaire & CDS & ISS & EIS \\
\hline Medical Officer & 14 & 10 & 9 \\
Company Nurse & 17 & 25 & 97 \\
Safety Officer & 44 & 39 & 18 \\
Manager & 32 & 30 & 2 \\
First Aider & 0 & 1 & 3 \\
Unspecified & 4 & 6 & 4 \\
\hline Total & 111 & 111 & 133 \\
\hline
\end{tabular}

CDS: Company Details Sheet.

ISS: Injury Summary Sheet.

EIS: Eye Injury Sheet. teen company sites (representing a workforce of 17,312 and including the largest site of 9,000 employees) did not provide a record of injuries during the previous year. Table II extrapolates the total injuries to include a probable grand total for the previous year. This places into perspective the representative nature of February 1991 as a prospective study period. Eye injuries account for $11.7 \%$ of the previous year's total, yet only $8.4 \%$ for the prospective month (where the reporting of individual cases was requested). This is probably attributable to slight underreporting of eye injuries for the study period.

The ISS requested 'Place in order of importance $(1>4)$ which type of injury is most likely to need hospital referral'. The results are shown in Table III. It is clear that a greater proportion of eye injuries, compared to other injuries, are perceived to need hospital attention.

During the prospective four week study period, a total of 133 eye injuries were sustained. During the same period, a total of 1,446 other injuries occurred. The approximate injury rate (all injuries) is 1 per 6,000 manhours at work, and for eye injuries the rate is approximately 1 per 75,000 man-hours at work, or 23 eye injuries per 1,000 population per year. Assuming annual working hours of 1,840 per person ( 46 weeks at 40 hours per week), this sample suggests that any individual is likely to suffer an eye injury only once in 40 years. Each employee in this sample therefore has only a slightly greater than even chance of suffering an eye injury at work during his or her working life.

Of the 133 injured during the study period, 115 (88.5\%) were male and 15 female. In three cases the sex was not recorded. The age range of those injured was 16 to 60 years, with a mean of 37 years. The age distribution is seen in Figure 1. The experience within the chemical industry, of those who were injured, ranged from 0 to 29 years, with a mean of nine years.

For the task being performed at the time of injury, a requirement for eye protection may have been stipulated by the employer. The eye protection status of the injured personnel at the time the injury occurred is recorded in Table IV. This information was not available in five cases. In 26 cases (19.5\%), the required eye protection was not

Table II. Injuries occurring during the study month and during the preceding year.

\begin{tabular}{lcrrr}
\hline & \multicolumn{3}{c}{ Study month } & \multicolumn{3}{c}{ Last year } \\
\hline Type of injury & No. of injuries (\% total) & \multicolumn{2}{c}{ No. of injuries (\% total) } \\
\hline Eye & 133 & $(8.4)$ & 1,417 & $(11.7)$ \\
Head \& neck & & & 1,154 & $(9.6)$ \\
Hand & $1,446^{*}$ & $(91.6)$ & 4,820 & $(40.0)$ \\
Others & & & 4,660 & $(38.7)$ \\
\hline Total & 1,579 & $(100.0)$ & 12,051 & $(100.0)$ \\
\hline Extrapolated total & $1,665 \dagger$ & & $16,633 \ddagger$ & \\
\hline
\end{tabular}

* Only the combined figure for non-ocular injuries was requested.

$\dagger$ Extrapolated to include (pro rata) the workforce of 3,254 for which this information was not provided.

$\ddagger$ Extrapolated to include (pro rata) the workforce of 17,312 for which the last year's data was not provided. 
Table III. Answers to the question: 'Place in order of importance $(1>4)$ which injury is most likely to need hospital referral:'

\begin{tabular}{lllll}
\hline Type of injury & \multicolumn{4}{l}{ Number of responses $\dagger$} \\
\hline & 1 st & 2nd & 3rd & 4 th \\
\hline Eye & $57^{*}$ & 13 & 13 & 11 \\
Head and neck & 16 & $36^{*}$ & 29 & 12 \\
Hand & 12 & 27 & $32^{*}$ & 22 \\
Other injuries & 9 & 20 & 17 & $44^{*}$ \\
\hline
\end{tabular}

* Most common response for this type of injury.

$\dagger$ Some priorities not specified.

being worn. In 67 cases $(50.4 \%)$, no protection was required, yet injury occurred. In 35 cases $(26.3 \%)$, the required protection was being worn, but the injury was not prevented. Twenty-one people sustained a chemical injury in a situation where no eye protection was required $(15.8 \%$ of all injuries). Twenty-one chemical injuries occurred in a situation where only BS $2092^{7}$ protection (unsealed protectors) were required ( $15.8 \%$ of all injuries). Three chemical injuries occurred to personnel who were wearing protection better than BS 2092. Two affected personnel wearing BS $2092 / \mathrm{G}$ or $2092 / \mathrm{C}$ and another wore a facemask with breathing apparatus.

The eye injury was unilateral in 113 cases, and bilateral in 20 . The injury required irrigation in 102 cases, removal of a foreign body in 25 , a topical antibiotic in 58 , and the application of a pad in four. In only 22 cases was Fluorescein stain used.

The EIS form requested the placement of the injury into one of several broad categories, and the results are shown in Table V. The EIS form also requested a brief description of the eye injury sustained, but unfortunately this section was often completed inadequately, and a more accurate statement on the casemix of injuries sustained is not possible. It is clear however, that the injuries ranged from trivial irritations, with or without foreign bodies, through corneal abrasions and corneoconjunctival burns, to eyelid lacerations and blunt injury. In 60 cases $(45.1 \%)$, the injury involved a chemical.

An unconfirmed number, but the vast majority, were initially treated by a nurse. One hundred and four were dealt with solely on site. Twenty-nine $(21.8 \%)$ required

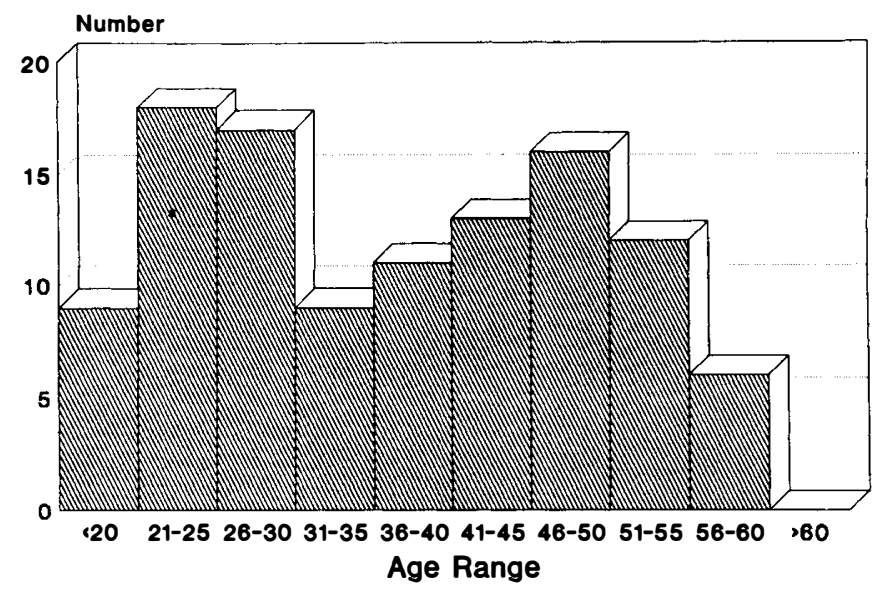

Fig. 1. The age distribution of injured personnel. attention from a doctor, 10 (7.5\%) from the company physician, $13(9.8 \%)$ at an eye hospital, and six (4.5\%) at a general accident and emergency department. A single medical or nursing consultation sufficed for 84 injured people $(63.2 \%)$, but $49(36.8 \%)$ required one or more follow-up visits, 41 by a nurse and eight by company physician or hospital doctor. No patient required hospital admission.

In 88 instances, the working time lost as a result of the injury was thirty minutes or less. In 20 cases the time lost was unspecified. Overall the mean time lost from work was 4.1 hours per injury. Five people required one day or more off work, the maximum being 30 days.

The EIS requested the opinion of the person completing the sheet, as to whether the injury might have been avoided if certain action had been taken. The choices, and the answers given, are shown in Table VI.

\section{DISCUSSION}

No previous study has followed a significant population for a time period and examined the incidence and causes of eye injury. The true incidence is therefore not known. In Wisconsin, Karlson and Klein ${ }^{8}$ reported a 'populationbased' study, the eye injuries actually being defined at a hospital department, as for previous UK papers ${ }^{1,3,4}$. Using the criterion of hospital attendance, the incidence of eye injury was calculated at 423:100,000 per year. Glynn et $a l .{ }^{9}$ in a telephone questionnaire survey in Massachusetts, found that the incidence of eye injuries requiring medical attention (though not necessarily hospital attendance) was 975:100,000 per year.

A small multi-centre survey in the $\mathrm{UK}^{10}$ suggested that the incidence was 613:100,000 per year for hospitaltreated injuries. Considering the difficulties of such studies, particularly in defining catchment populations for

Table IV. The eye protection status of the injured.

1. Injured personnel who wore no protection, but should have done.

Recommended protector Number of
BS 2092 (general industrial)
BS 2092 G/C (sealed against gas/chemical)
Facemask protector
Facemask + breathing apparatus
Whole body protection
BS 679 (Welding protector)
Unspecified protection
Subtotal

2. Injured personnel who wore protection as recommended.

Recommended protector Number of injuries

No protector required 67

BS 2092 (general industrial) 26

BS $2092 \mathrm{G} / \mathrm{C}$ (sealed against gas/chemical) 4

Facemask protector

Facemask + breathing apparatus 1

Whole body protection

BS 679 (Welding protector)

Unspecified protection

Subtotal

uries

2

1

26 
Table V. The type of eye injury sustained.

\begin{tabular}{lc}
\hline Injury type & Number of injuries \\
\hline Chemical & 60 \\
Foreign body & 59 \\
Blunt injury & 6 \\
Lacerations & 4 \\
Welding flash & 3 \\
Hot water scald & 1 \\
\hline Total & 133 \\
\hline
\end{tabular}

emergency services, the similarity between these figures is striking. However, the true incidence of injury, treated or untreated, is not known for any population. The United Kingdom lacks an injury surveillance scheme such as exists in the USA. We rely upon extrapolation from small studies such as this and others. A proper data collection mechanism is of importance for the future, and can only be effectively organised by the special eye hospitals.

This study has surveyed a special group of people in a particular environment, but is truly population-based. In general terms the study sample of 63,000 is small, being approximately $0.1 \%$ of the population of the United Kingdom. However, the timescale of the survey is such that approximately 10 million man-hours of work have been studied. Within the context of occupational eye injury, and specifically within this type of industry, the sample is significant. However nearly $75 \%$ of companies contacted declined to participate in this study. The reasons for this are not known, but the data presented should be interpreted with this in mind.

For this sample, an eye injury incidence of approximately one per 75,000 man-hours at work has been shown, that is, the likelihood of suffering on average, only about one eye injury during a working life. This very low incidence, and the rarity of severe injury in those who are injured, must partly explain the problem of the inadequate use of eye protection where recommended. The average employee will have little or no experience of eye injury in himself or his colleagues, and very few workers will have first or second-hand experience of a severe injury. It is therefore clear that the continuing education of employees into the potential dangers of eye injury, including regular information on safety protocols and protection instructions, is of paramount importance if any significant reduction in the incidence of occupational injury is to be achieved.

In this population, $14.3 \%$ of injuries required hospital attention, and in total $21.9 \%$ of injuries received attention from a doctor. The availability on site of medical and nursing staff will modify the referral rate. However, for this population, nearly $80 \%$ of eye injuries never reach hospital. Such a proportion has not been defined in any previous study. The assumption that all eye injuries not reaching hospital are trivial, is a tempting one, and probably broadly accurate. However, the occasional patient with late retinal detachment secondary to dialysis, angle recession glaucoma, secondary hyphaema or simply the corneal sequelae of multiple injuries, witness the fact that this is not necessarily so.
Information on the eye protection status of the injured personnel is shown in Table IV. In general, the information was given by the injured party himself. It should be noted that most large companies treat the disregard of protective regulations as a disciplinary matter ${ }^{11}$. The information collected from the injured party must therefore be interpreted with this in mind. The admission that the regulation protector was not being worn is an admission of guilt. In the opinion of the authors it is likely that fewer than 35 perconnel were wearing protection when the injury occurred.

Despite the need to interpret these figures, several important points arise from the data on eye protection. Firstly, a high number of personnel $(67,50.4 \%)$ were injured in situations where no ocular protection was recommended and none was being worn. Clearly not all eye injuries are avoidable, and the risk of eye injury should not be exaggerated. However, the need for eye protection in given work situations should be constantly reappraised. Eye protectors are not popular ${ }^{12,13}$. Protectors may be uncomfortable, may mist, may restrict field of view, or may simply be perceived as inconvenient or unnecessary. Constant eye protection is not necessary for all workers, but sensible usage must constantly be pursued.

Secondly, a total of 26 personnel (perhaps more) were injured because they were wearing no eye protection in a situation where the need for eye protection was clearly stated. In two cases the required protection was facemask with breathing apparatus, and whole body protection, respectively. While trivial injury resulting from the absence of protective spectacles must be expected to happen occasionally, the absence of such essential protection must be avoided wherever possible. Clearly an accident could prove fatal. These small but significant figures demonstrate the continued need for vigilance, education, and the use of disciplinary proceedings where appropriate.

Thirdly, and perhaps of most concern, is that 35 personnel (perhaps fewer, see above) were apparently wearing a recommended protector, but were injured nevertheless. There are several implications here. It is clearly a possibility that the 'recommended' protector is actually inadequate to protect fully in that situation, and that a different type of protector should have been recommended (for instance, BS 2092 protectors [unsealed] being used in a situation where sealed goggles [against gas or chemical, BS 2092/G, BS 2092/C] were more appropriate). Guidelines are available for the selection, usage and maintenance of protectors ${ }^{14}$. It is certain that a protector, through

Table VI. Answers on EIS to the question: "Could this injury have been avoided by any of the following?:"

\begin{tabular}{lcc}
\hline Option & Yes* & $\begin{array}{c}\text { (\% of } \\
\text { Injuries) }\end{array}$ \\
\hline 1. Proper safety wear should have been worn & 35 & $26.3 \%$ \\
2. Better safety wear was needed & 25 & $18.8 \%$ \\
3. Safer work practice should have been followed & 53 & $39.8 \%$ \\
4. Better awareness of dangers was necessary & 44 & $33.1 \%$ \\
5. Discipline of persistent offenders & 13 & $9.8 \%$ \\
6. Better labelling of dangerous environments & 4 & $3.0 \%$ \\
7. Better shielding of equipment & 9 & $6.8 \%$ \\
\hline
\end{tabular}

* Any number of options, from $0-$ all 7 , could be chosen. 
age and wear and tear, may cease to perform adequately. Protectors need checking regularly and should be replaced where any doubt exists. It is also a possibility that a given protector, designed to fulfil a certain function and bearing certification to document this (for example a British Standards Institution Kitemark) may perform inadequately. Such a problem is clearly in need of thorough investigation, and the certifying authority should always be informed of any shortcomings, and given details of the guilty protector.

Table VI makes it clear that those treating the eye injuries feel that there is considerable room for improvement. In $39.8 \%$ of injuries, work was being performed dangerously. In $33.1 \%$, the injured workers were poorly informed about the risks they were taking. In $26.3 \%$ they should have been wearing protectors, and in $18.8 \%$ of cases, the protection appeared to be inadequate.

Under the Protection of Eyes Regulations $1974^{2}$, an employer is required to provide, maintain and replace, eye protection for certain tasks, and to ensure that employees use it. It is the responsibility of the employee to take care of the protector, ensure it is replaced if damaged, and wear it at all appropriate times. It is clear that this utopian situation does not actually exist. This study demonstrates the continued need for vigilance amongst employers and employees, to view critically every situation where eye injury is a risk, to isolate as many workers as possible from that risk, to use equipment and fixed shielding wherever possible, and only as a last resort to rely upon personal eye protection, which should always be stringently tested and appropriate for its designated task. Employees have a responsibility to work safely and to use protection in all at risk situations.

Despite the introduction of legislation to prevent injury ${ }^{2}$, increasingly responsible employers and betterinformed employees, the availability of high-grade ocular protection and a wealth of experience in protection generally, occupational injuries still account for the majority of eye trauma, for a substantial part of hospital eye service resources, and for considerable morbidity. That so few of these injuries now require inpatient care is encouraging, but there is still much to be done. This paper has studied workers within a particular environment which may not carry a high intrinsic risk of injury (the incidence is 23:1,000:year). Other processes have been found to have a much higher injury rate (eg metal workers, 60:1,000:year ${ }^{15}$. Differences in injury rate may be a function of intrinsic risk balanced against variable safety practices and will be open to various interpretations. The problems of small companies with inadequate resources for safety, of the self-employed, of the ill-informed employee, or merely of the worker who regards multiple eye injury as an acceptable hazard, have not been approached. It is these who most need to be educated.

We are grateful to the medical officers, nursing sisters and safety officers of all companies who participated in this study. We are obliged to the Chemical Industries Association for organising the distribution and collection of questionnaires. We are particu- larly indebted to Dr A. E. Smith, Chairman, Medical Working Group, CIA for making this study possible. The following companies are organisations who participated in the survey:

Abbott Laboratories Ltd; Air Products plc; Albright \& Wilson Ltd; The Alumina Company Ltd; Anchor Chemical (UK) Ltd;

Associated Octel Company Ltd; BASF plc; William Blythe \& Co. Ltd; The Boots Company plc; BP Chemicals Ltd; British Chrome \& Chemicals Ltd; Capper Pass \& Son Ltd; Chemoxy International plc; Ciba-Geigy plc; Clayton Aniline Co.; Coates Brothers Ltd; Countdown Clean Systems Ltd; Crosfield Chemicals Ltd; Dow Corning Ltd; Du Pont (UK) Ltd;

Enichem Elastomers Ltd; Exxon Chemical Ltd;

Fisons Scientific Equipment Ltd; R \& J Garroway Ltd; Glaxochem Ltd; Glebe Mines Ltd;

Gramos Chemicals International Ltd; Hoechst UK Ltd; Johnson Matthey plc; Laporte Industries Ltd;

Macfarlan Smith Ltd; Mebon Ltd; Morton International; MTM plc; Quest International; Reckitt \& Coleman Ltd; Reckitt's Colours Ltd; Reddish Savilles Ltd; Remtox (Chemicals) Ltd; Robinson Brothers Ltd; Rohm \& Haas (UK) Ltd; Schering Agrochemicals Ltd; SCM Chemicals Ltd; Shell Chemicals UK Ltd; Smithkline Beecham Pharmaceuticals;

Sovereign Chemical Industries Ltd; Sterling Organics Ltd; Sterling Roncraft Ltd; Synthetic Chemicals Ltd; Synthite Ltd; Tekchem; Tioxide Chemicals (UK) Ltd; Wellcome Foundation Ltd

\section{REFERENCES}

1. Garrow A. A statistical enquiry into 1,000 cases of eye injuries. Br J Ophthalmol 1923, 7: 65-80.

2. Factories: The protection of eyes regulations 1974. HMSO 8/P15259/9H99 K200 5/75, London 1975

3. Lambah P. Adult eye injuries at Wolverhampton. Trans Ophthalmol Soc UK 1968, 88: 661-73.

4. Canavan YM, O'Flaherty MJ, Archer DB, Elwood JH. A 10-year survey of injuries in Northern Ireland 1967-76. Br J Ophthalmol 1980, 64: 618-25.

5. MacEwen CJ. Eye injuries: a prospective survey of 5,671 cases. Br J Ophthalmol 1989, 73: 888-94.

6. Jones NP, Hayward JM, Khaw PT, Claoué CMP, Elkington AR. Function of an ophthalmic 'accident and emergency' department: results of a six month survey. $\mathrm{Br} \operatorname{Med} J 1986$, 292: 188-90.

7. British Standard 2092:1967. Specification for industrial eye-protectors. British Standards Institution, London 1967.

8. Karlson TA and Klein BE. The incidence of acute hospitaltreated eye injuries. Arch Ophthalmol 1986, 104: 1473-6.

9. Glynn RJ, Seddon JM, Berlin BM. The incidence of eye injuries in New England adults. Arch Ophthalmol 1988, 106: 785-9.

10. Anon. A nationwide survey of the causes and circumstances of eye injuries. Ergo Research Consultants, Oxford 1990.

11. Jones NP. Effectiveness of eye protection in the metalworking industry (Letter). Br Med J 1990, 301:931.

12. Banerjee A. Effectiveness of eye protection in the metal working industry. $\mathrm{Br}$ Med J 1990, 301: 645-6.

13. Liu C, Davison C, Cooling R. Eye protection in the metal working industry (Letter) $\mathrm{Br}$ Med J 1990, 301: 1048.

14. Brtish Standard $7028 ; 1988$. Guide for selection, use and maintenance of eye-protection for industrial and other uses. British Standards Institution, London 1988.

15. Harker C, Matheson A, Ross J, Seaton A. Eye protection in the metal working industry (Letter). Br Med J 1990, 301: 1048 . 